\title{
Non-Cooled Power System for Venus Lander
}

\author{
Denise Salazar* \\ The University of Texas at Austin, TX 78705 \\ Geoffrey A. Landis ${ }^{\dagger}$ \\ NASA John H. Glenn Research Center, Cleveland, OH 44135 \\ and \\ Anthony J. Colozza \\ Vantage Partners, LLC, Cleveland, OH 44315
}

The Planetary Science Decadal Survey of 2013-2022 stated that the exploration of Venus is of significant interest. Studying the seismic activity of the planet is of particular importance because the findings can be compared to the seismic activity of Earth. Further, the geological and atmospheric properties of Venus will shed light into the past and future of Earth. This paper presents a radioisotope power system (RPS) design for a small low-power Venus lander. The feasibility of the new power system is then compared to that of primary batteries. A requirement for the power source system is to avoid moving parts in order to not interfere with the primary objective of the mission - to collect data about the seismic activity of Venus using a seismometer. The target mission duration of the lander is $\mathbf{1 1 7}$ days, a significant leap from Venera 13, the longest-lived lander on the surface of Venus, which survived for 2 hours. One major assumption for this mission design is that the power source system will not provide cooling to the other components of the lander. This assumption is based on high-temperature electronics technology that will enable the electronics and components of the lander to operate at Venus surface temperature. For the proposed RPS, a customized General Purpose Heat Source Radioisotope Thermoelectric Generator (GPHSRTG) is designed and analyzed. The GPHS-RTG is chosen primarily because it has no moving parts and it is capable of operating for long duration missions on the order of years. This power system is modeled as a spherical structure for a fundamental thermal analysis. The total mass and electrical output of the system are calculated to be 24 kilograms and 26 Watts, respectively. An alternative design for a battery-based power system uses Sodium Sulfur batteries. To deliver a similar electrical output for $\mathbf{1 1 7}$ days, the battery mass is calculated to be 234 kilograms. Reducing mission duration or power required will reduce the required battery mass. Finally, the advantages and disadvantages of both power systems with regard to science return, risk, and cost are briefly compared. The design of the radioisotope power system is considerably riskier because it is novel and would require additional years of further refinement, manufacturing, safety analysis, and testing that the primary batteries do not need. However, the lifetime of the radioisotope power system makes its science return more promising.

\footnotetext{
* NASA Space Academy 2013, NASA Glenn Research Center, Cleveland OH. AIAA Student Member.

${ }^{\dagger}$ NASA John Glenn Research Center, mailstop 302-1, 21000 Brookpark Road, Cleveland OH 44315. AIAA Associate Fellow.

‡ Vantage Partners, LLC, John Glenn Research Center, mailstop 309-1, 21000 Brookpark Road, Cleveland OH 44135
} 


\section{Acronyms}

$\begin{array}{ll}\text { GIS } & =\text { Graphite Impact Shell } \\ \text { GPHS } & =\text { General Purpose Heat Source } \\ \text { MEL } & =\text { Mass Equipment List } \\ \text { NaS } & =\text { Sodium Sulfur } \\ \text { PbTe } & =\text { Lead Telluride } \\ \text { PG } & =\text { Pyrolytic Graphite } \\ \text { QTY } & =\text { Quantity } \\ \text { RPS } & =\text { Radioisotope Power System } \\ \text { RTG } & =\text { Radioisotope Thermoelectric Generator } \\ \text { SiGe } & =\text { Silicon Geranium alloy } \\ \text { SiMo } & =\text { Silicon Molybdenum alloy } \\ \text { TE } & =\text { Thermoelectric } \\ \text { TRL } & =\text { Technology Readiness Level } \\ \text { ZT } & =\text { Figure of Merit }\end{array}$

\section{Nomenclature}

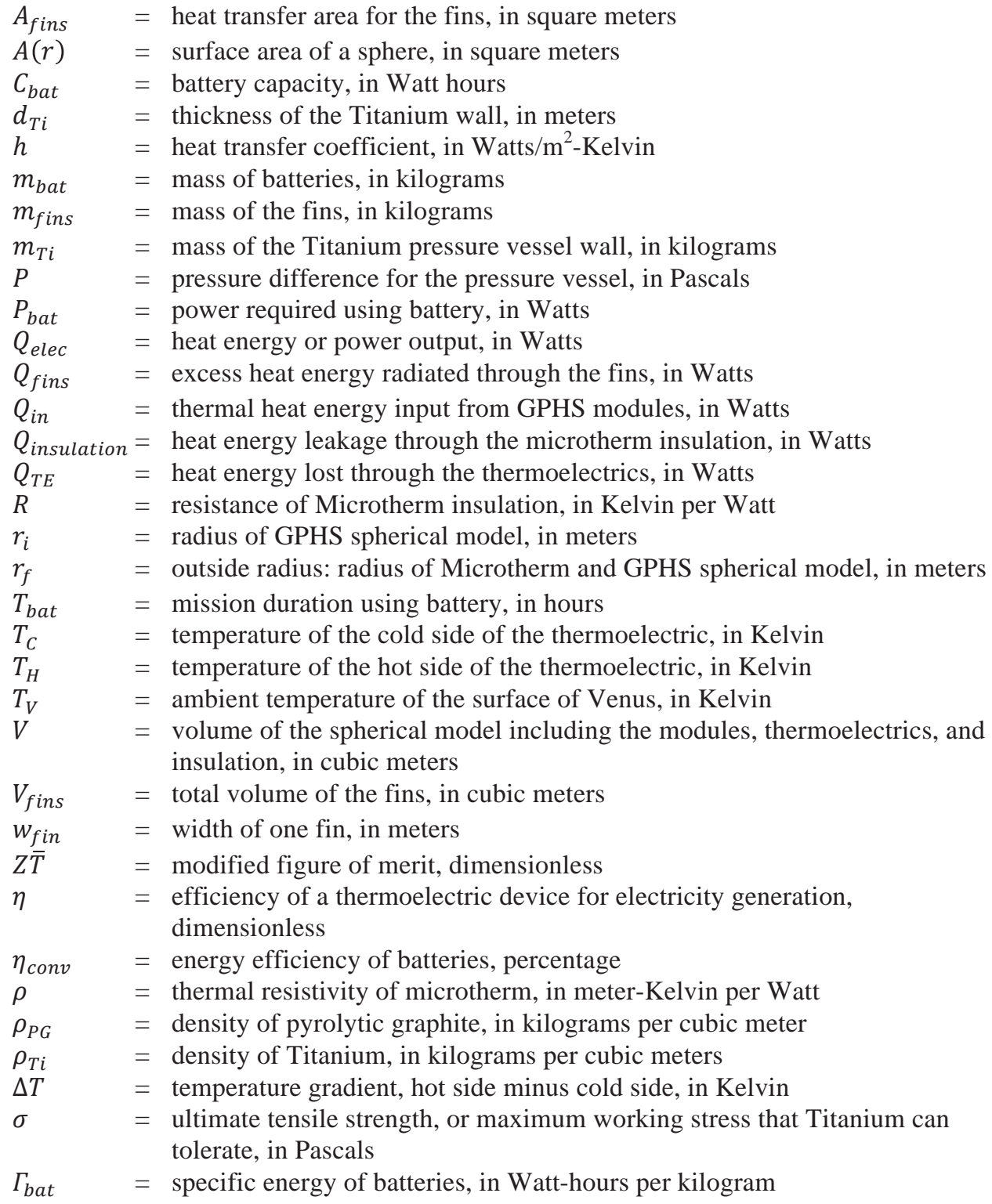




\section{Introduction}

$\mathrm{T}$ he Planetary Science Decadal survey of 2013-2022 stated that an in-situ mission to Venus is one of five top candidates for future missions. ${ }^{1}$ Even though Venus is the planet most similar to the Earth in size and density, high temperatures and pressures at the surface make it also extremely harsh surface environment ${ }^{2}$. Obtaining science from the surface is a difficult task to design and implement. However, it is also invaluable and a mission to Venus is of interest to the science community. The geological and atmospheric properties of Venus will shed light into the past and future of Earth. Therefore, a mission to Venus in the Discovery class is proposed for a 2020 launch.

The Russian Venera landers from 1961 to 1983 stand out as successful past missions to Venus. The Venera 4 probe was the first to conduct direct sampling of the atmosphere of Venus. ${ }^{\S}$ The Venera 7 lander was the first manmade object to return data to Earth after landing on another planet. ${ }^{\S}$ The Venera 9 orbiter was the first spacecraft to orbit Venus and the lander the first mission to transmit photographs from the surface of another world. ${ }^{\S}$ The Venera 13 lander, which survived for 127 minutes is the longest-lived lander ever to survive on Venus.. Other past missions to Venus include the orbiter and probes of Pioneer Venus (1978), the landers and balloons of Vega 1 and 2 (1984), the Magellan orbiter (1989) and Venus Express (2005), and the fly-bys of Galileo (1989), Cassini (1997), and Messenger (2004). ${ }^{\S}$ It has been about three decades since the last lander to Venus and it is time to design another mission to touchdown on the planet.

The present study analyzes a power system for a Venus surface lander ${ }^{3}$, consisting of a relay orbiter, a descent package, and a lander. The lander will be designed to live for 1 Venus solar day, or 117 Earth days, which is a significant leap from the survival time of the longest lived lander on the surface of Venus to date. The primary objective of the mission will be to record seismic activity with a seismometer. This mission presents a significant challenge to the power system design.

\section{Venus Environment}

The surface of Venus has an average temperature of 450 degrees Celsius $(723.15 \mathrm{~K})$ at an atmospheric pressure of about 92 bars. The temperature is hot enough to melt lead, and the pressure is 92 times the pressure found on the surface of Earth. Even though no human could survive in these extreme conditions, a robot could plausibly be designed to withstand these conditions. The atmosphere of Venus is composed primarily of carbon dioxide and its clouds contain sulfuric acid droplets. The structure of the Venus atmosphere is shown in Fig. $1{ }^{4}$ The sulfuric-acid cloud layers in the middle atmosphere prevents the majority of sunlight from reaching the surface. The wind speeds reduce significantly to about 0.3 to 0.6 meters per second at the surface. It is a challenging task to design a lander that will survive for a long duration on the surface. The surface temperature and pressure are hurdles to overcome or adapt to.

This study analyzes the possible power systems for a Venus surface mission.

\section{Power System Study}

This study analyzes the possible power systems for a lander on the surface of Venus that will survive for at least 1 Venus solar day. Previous studies have analyzed the use of a radioisotope power system (RPS) for use on the surface of Venus. ${ }^{5,6,7,8,9,10}$ However, all of them required the power system to provide cooling to other components of their spacecraft, especially the science package. ${ }^{11}$ This study ${ }^{3}$ is different in that no cooling will be provided. This assumption is based on use of high

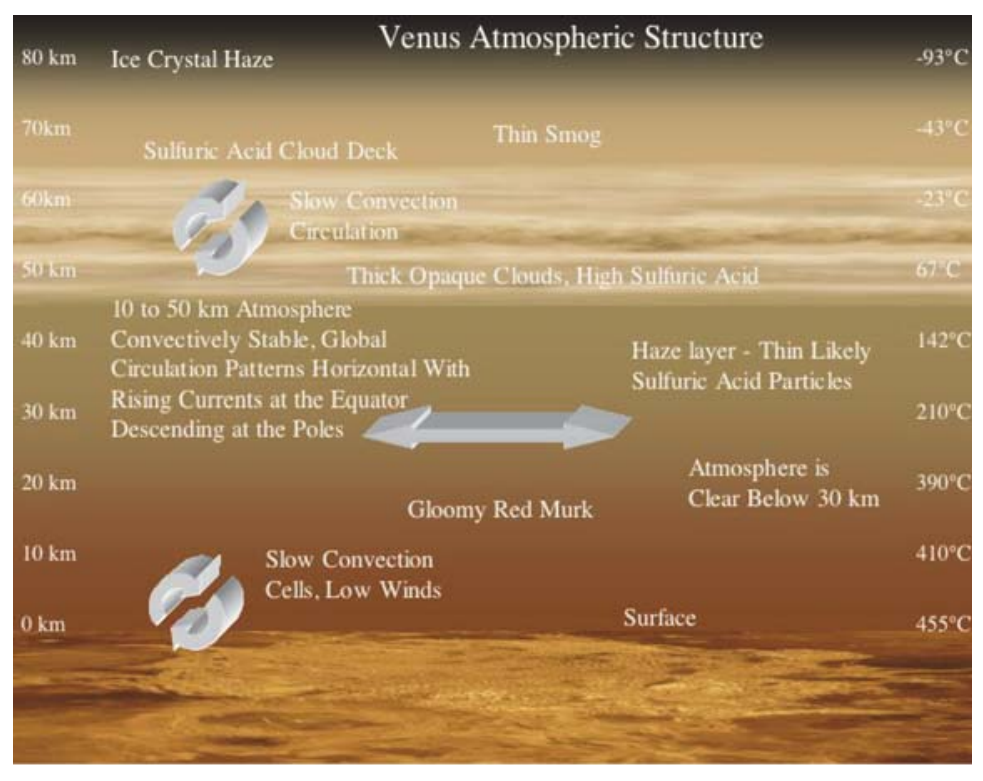

Figure 1. Atmospheric profile of Venus ${ }^{10}$.

${ }^{\S}$ http://nssdc.gsfc.nasa.gov/planetary/planets/venuspage.html 
temperature electronics technology that will enable the electronics and components of the lander to operate at Venus ambient temperature at the surface. ${ }^{12,13}$

\section{A. Requirements}

- The power system shall operate on the surface of Venus for 1 Venus solar day (117 Earth days).

- The power system shall operate at the Venus ambient temperature of 450 degrees Celsius (723 K) and pressure of 92 bars.

- The unshielded part of the power system shall be coated for protection from the corrosive environment.

- The power system shall have no moving parts to reduce the likelihood of failure inherent in such parts. The seismometer shall then avoid vibrations from the power system.

- The intended target for the lander and descent package will be the North Polar regions. This region is chosen to allow communications via a relay orbiter placed in a polar elliptical orbit, with apoapsis over the North pole.

\section{B. Assumptions}

- It is assumed that the components of the lander will not require any cooling. They will be able to operate at Venus ambient temperatures and pressures. Therefore the power system will not be required to provide cooling to the components.

- The power levels required for the mission will be low. An initial baseline estimate of power required is 20 Watts.

\section{Trades}

Two cases were analyzed and then compared: RPS for Case 1, and primary batteries for Case 2 . Case 1 typically operates on the order of years and therefore meets the first requirement. A customized GPHS-RTG system that also meets the second, third, and fourth requirements was designed in this paper. It is assumed that all the electronics and sensors will operate at Venus ambient temperatures and pressures. This assumption is driven by high-temperature electronics technology that is expected to be fully operational by the time frame of the design phase for this mission. ${ }^{13,14}$ Eliminating cooling from the lander will reduce its mass and power consumption.

The second power system case considered using high temperature primary batteries. This case depends on mission duration. It may be a better choice if the length of time needed for the seismometer to record a sufficient amount of data is on the order of hours, days, or even months. The design for Case 2 is also significantly simpler than the design for Case 1. The benefits of using batteries versus the battery mass needed for 117 days will be discussed.

Another option that will not be explored is a solar array and battery combination because of the landing location at the North Pole. Although the use of solar arrays may be a feasible choice at the equator, ${ }^{14}$ it is not a feasible choice near the polar regions due to the low sun angle.

\section{Case 1: Radioisotope Power System}

A customized General Purpose Heat Source Radioisotope Thermoelectric Generator (GPHS-RTG) is chosen as the RPS for Case 1. RPS have been used in many earlier missions, are capable of operating for long duration missions, on the order of years, and have no moving parts. Figure 2 displays a cutaway view of a GPHS-RTG. ${ }^{17}$ A GPHS-RTG contains 18 stacked GPHS modules which contain a heat source. ${ }^{17}$ The modules are surrounded by thermoelectric materials that convert a temperature differential between a "hot side" heated by the isotope, and a "cold side" rejecting heat into the environment, into an electrical output. The "cold side" temperature of 450 degrees Celsius at the surface of Venus causes the temperature differential for the thermoelectrics to decrease, and therefore the efficiency of the thermoelectrics to decrease as well. However, the decrease in efficiency is not enough to rule out the customized GPHS-RTG as a feasible power source. 


\section{GPHS module}

GPHS modules are the isotope heat source for the GPHS-RTG. Each GPHS module contains 0.6 kilograms of $\mathrm{Pu}^{238} \mathrm{O}_{2} \cdot{ }^{15}$ The dimensions of one GPHS module are 9.96 by 9.43 by 5.82 centimeters. ${ }^{15}$ Figure 3 shows an expanded view of a GPHS module. ${ }^{16}$ Each GPHS module has 4 fuel pellets. Each pellet is encapsulated in an iridium alloy clad that will resist oxidation in the event of an impact and accident. ${ }^{17}$ The fuel pellet and iridium alloy clad together are called the fueled clad. Two fueled clads are contained within in a Graphite Impact shell (GIS) which also provides protection in case of an accident. Two GISs are contained within an aeroshell made of carbon material. ${ }^{16}$ The customized GPHS-RTG for this lander will use two GPHS modules. Each module produces an initial thermal heat output of about 250 Watts. ${ }^{18}$ Therefore, the customized GPHS-RTG for the lander will produce an initial thermal heat energy of about 500 Watts.

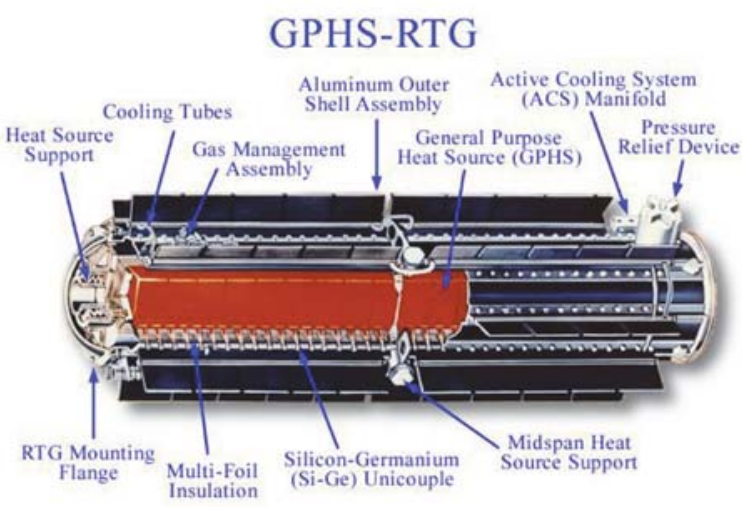

Figure 2. Cutaway view of a GPHS-RTG.

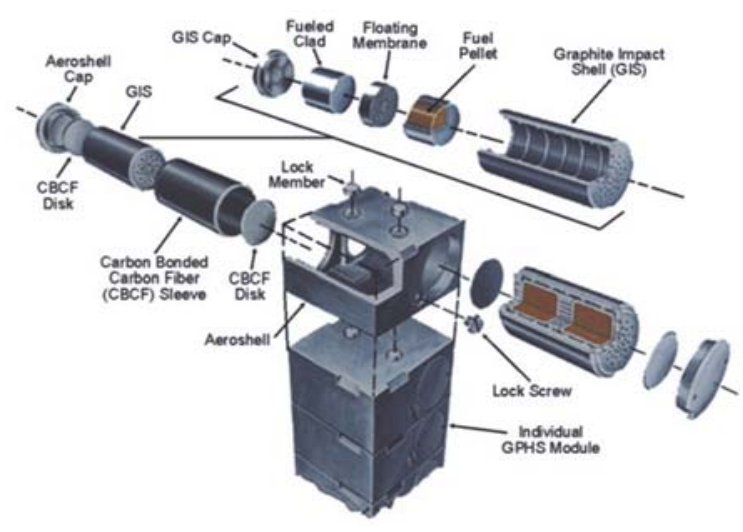

Figure 3. Expanded view of a GPHS module.

\section{Thermoelectric Converter}

A thermoelectric material creates an electric potential from a temperature differential. There are two junctions, the hot shoe and the cold shoe, that are joined by two metals. The GPHS module is the heat source to the hot shoes and therefore the hot shoes are in contact with the GPHS module. Thermoelectric converters have low efficiencies compared to dynamic systems such as Stirling converters, but have no moving parts.

For high temperature operation, such as on Venus, Silicon Geranium ( $\mathrm{SiGe}$ ) thermoelectric materials will perform well. Lead Telluride (PbTe) was excluded as a possible material for this group because its maximum operating temperature is $900 \mathrm{~K}$, well below the hot junction temperature of the GPHS modules $(1275 \mathrm{~K}){ }^{19} \mathrm{SiGe}$ material is one of the few that function at high temperatures. It also has a flight history of operating on missions from Viking to Galileo, and therefore the reliability and technology readiness is well demonstrated. For this study, a p-type SiGe metal alloy leg and an n-type SiGe metal alloy leg are chosen. Figure 4 displays an expanded view SiGe thermoelectric that was used on a GPHS-RTG. ${ }^{17}$ The hot shoe is made of Silicon-Molybdenum (SiMo). The cold shoe is a stack assembly of tungsten, copper, molybdenum, stainless steel, and alumina parts. The total length of the $\mathrm{SiGe}$ thermocouple is 3.11 centimeters. The largest cross section of the thermocouple is located at its hot shoe: 2.9 by 2.9 centimeters. A full description of SiGe thermoelectric materials and its dimensions can be found in reference 10 .

The thermoelectric material's ability to produce power is characterized by its figure of merit (ZT). This can be seen in Fig. 5. ${ }^{20}$ Figure of merit depends on the properties of the thermoelectric material. It takes into account thermal conductivity and electrical conductivity of the material. The higher the figure of merit, the more efficiently the material is able to produce thermoelectric power. As shown in Fig. 5, SiGe can operate at high temperatures. The standard GPHS-RTG used on missions in the 1970s has 576 thermoelectrics and 18 modules. For the power level required here, we estimate that each module needs 32 thermoelectrics. The arrangement of the thermoelectrics around the module will not be analyzed. In a typical GPHS-RTG the unicouples are connected in two series-parallel electric wiring circuits. ${ }^{16}$

The temperatures that are utilized in a thermal analysis later in this paper is displayed in Table 1 . The hot junction of the thermoelectrics is the heat provided by the GPHS modules. The cold junction of the thermoelectrics 
is designed to be 50 Kelvin higher than the ambient temperature at the surface of Venus. From Fig. 5, at the average temperature of about 1000 Kelvin, the $\mathrm{ZT}$ for SiGe is about 0.7 .

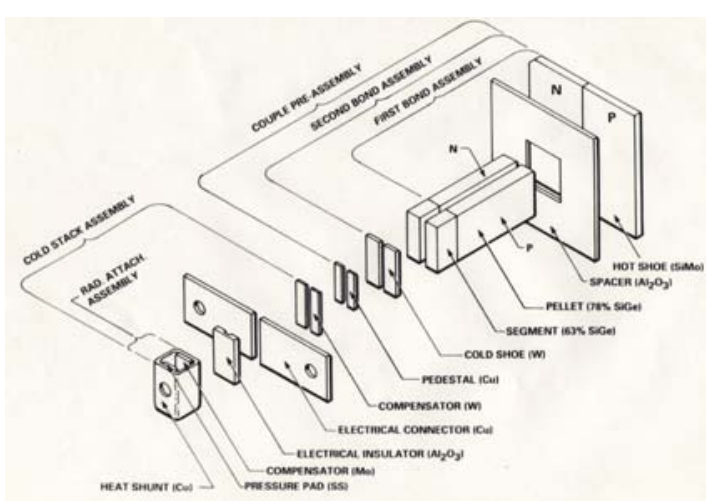

Figure 4. Expanded view of a SiGe thermocouple.

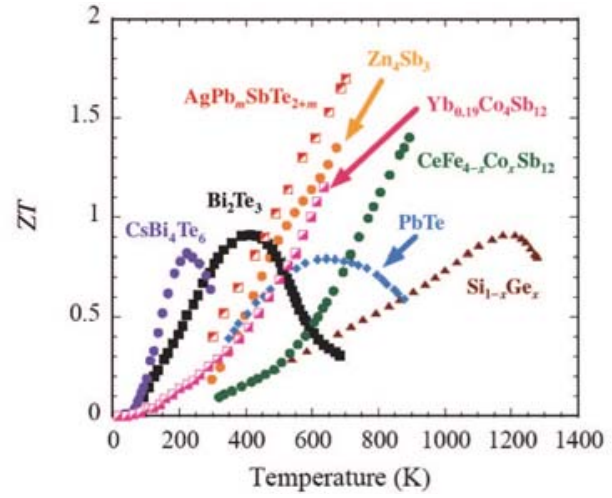

Figure 5. Figure of merit $\mathrm{ZT}$ versus temperature for several thermoelectric materials.

Table 1. Summary of important temperatures.

\begin{tabular}{|l|l|}
\hline Hot Junction of the thermoelectrics & 1275 Kelvin \\
\hline Cold Junction of the thermoelectrics & 773 Kelvin \\
\hline Ambient temperature at surface of Venus & 723 Kelvin \\
\hline Average temperature of the junctions & 1024 Kelvin \\
\hline
\end{tabular}

\section{A3. Insulation/Wall/Coating/Fins}

Since the thermoelectric conversion relies on a temperature difference between the hot (GPHS) and cold (Venus environment) sides, it is necessary to insulate the GPHS to keep the heat from leaking away to the environment: any heat lost by conduction to the environment represents power lost, rather than available to be converted to electrical power. The insulation chosen to surround the modules and thermoelectrics is Microtherm Super A insulation. ${ }^{* *}$ This material will survive on the surface of Venus because its maximum temperature limit is $1423 \mathrm{~K}$ for long term exposure. ${ }^{* *}$ It has a thermal conductivity of $0.0435 \mathrm{~W} / \mathrm{m}-\mathrm{K}$ at $1073 \mathrm{~K}$, and a density of $450 \mathrm{~kg} / \mathrm{m}^{3}{ }^{* *}$ This thermal

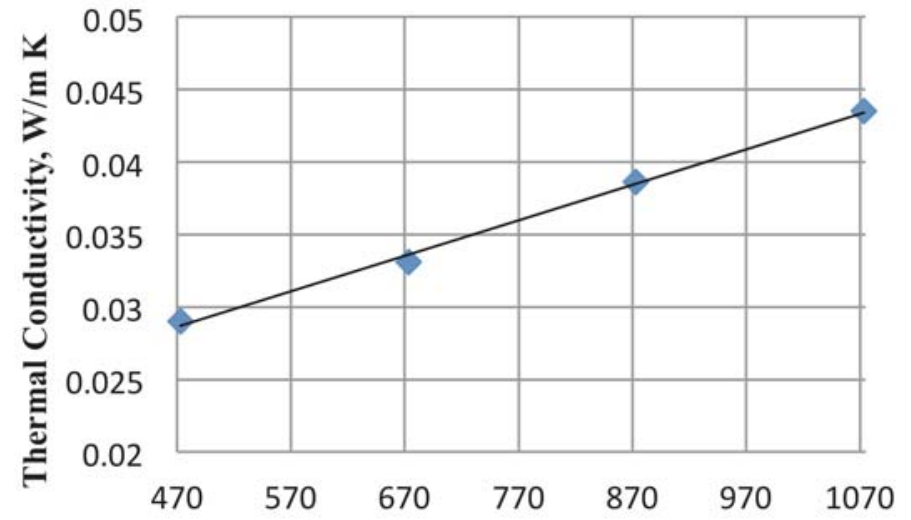

Temperature, $\mathbf{K}$ insulation is an excellent choice for this RPS because it has very low thermal conductivity at extremely high temperatures. It is important to note that the thermal conductivity of the Microtherm insulation is dependent on temperature. Fig. 6 displays this relationship.** Another possible form of insulation not considered is aerogel. Although lighter than Microtherm it was considered riskier for this mission because of its lower level of development.

\section{Figure 6. Thermal conductivity of Microtherm versus temperature.}

\footnotetext{
*** Microtherm Inc. Microtherm Super A product characteristics at: http://www.microthermgroup.com/high/EXEN/site/products-detail.aspx?vPK=31\&k=3\&l=1. 
The Microtherm insulation needs to be kept in vacuum in order to function optimally. The carbon dioxide in the atmosphere of Venus will cause the thermal conductivity of the insulation to increase, which is not desired. A pressure vessel will be used to allow the insulation to function and protect it from the atmosphere of Venus. One of the difficulties of the extreme environment of Venus is that its temperature would melt, crush, and destroy common materials for most spacecraft. Titanium is the chosen material for the vessel due to its high strength, low thermal conductivity, and a melting point of about $1900 \mathrm{~K}$, well above the ambient temperature of the surface of Venus.

Fins will surround the titanium wall to radiate waste heat from the cold side of the thermocouple to the environment. Pyrolytic Graphite (PG) is the material chosen for the fins, because it has a thermal conductivity of $1700 \mathrm{~W} / \mathrm{m}-\mathrm{K}$ and it is stable up to 2200 degrees Celsius (2493 K). ${ }^{\dagger \dagger} \mathrm{PG}$ has a density of $2220 \mathrm{~kg} / \mathrm{m}^{3}$. $^{+\dagger}$ The outer layer of the wall and the fins will be coated with a film of gold for acid resistance. Gold is chosen for the coating because it is one the least reactive metals, is corrosion resistant, and has a melting point well above the ambient temperature of the surface of Venus. The gold coating on the titanium wall and fins will protect the power system from the corrosive Venus environment. The design also has a gas management valve to allow Helium, a byproduct of the radioactive decay of Plutonium-238, to escape during the pre-launch and cruise phases (this is considered not critical during the mission phase). .

\section{Spherical Model}

For simplicity the power generator was modeled as a spherical structure for a fundamental thermal analysis as a first-look at what this design will entail. Figure 8 shows an overall schematic of the power system. Note that this figure is not drawn to scale. The fins are hooplike structures around the spherical model. However they will be sized as rectangular shaped later in this paper in order to obtain their approximate mass. The figure shows one thermoelectric element of the 64 in the system (32 per module). The following assumptions were made:

- Two GPHS stacked on top of each other have the approximate dimensions of 10 $\mathrm{cm}$ by $10 \mathrm{~cm}$ by $10 \mathrm{~cm}$. The diameter of the central sphere for the thermal model is chosen to equal the diagonal of this cube, 0.0866 meters, and hence the GPHS modules fit inside the central sphere

- $\quad$ The insulation surrounding the modules was modeled as a sphere. The thickness

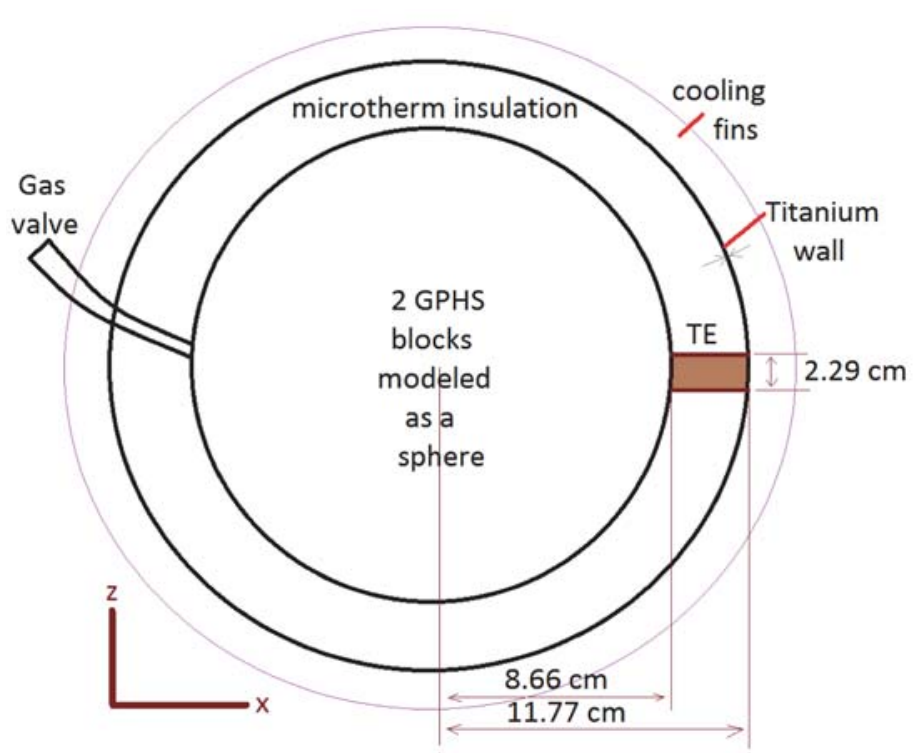

Figure 7. Cut out section of the customized GPHS-RTG power system.

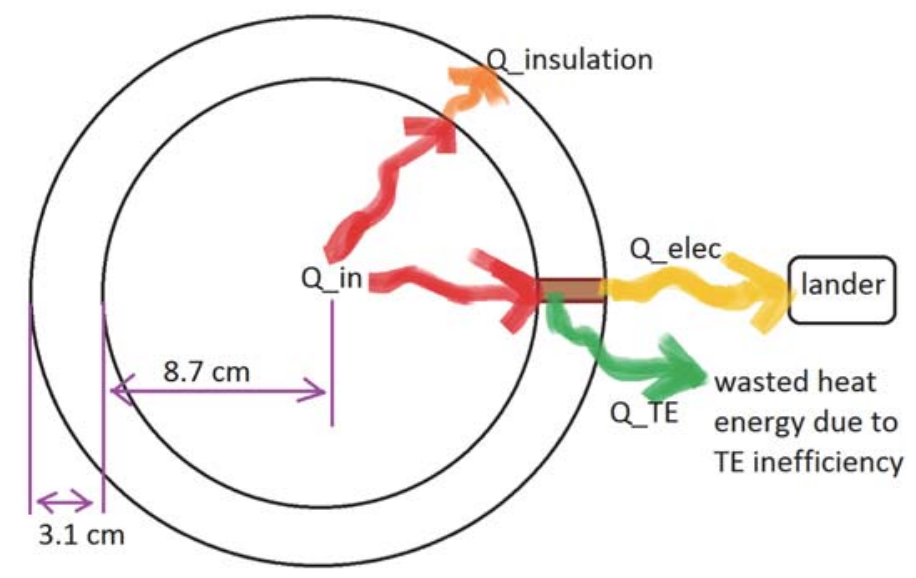

Figure 8: Heat transfer elements of the customized GPHSRTG.

\footnotetext{
${ }^{\dagger}$ Minteq Pyrogenics Group. Product characteristics at: http://www.minteq.com/our-products/minteq-pyrogenicsgroup/pyroid-pyrolytic-graphite/
} 
of the insulation is equal to the length of the SiGe thermoelectrics: 0.0311 meters. ${ }^{17}$

- The thermal conductivity of the Microtherm insulation was assumed to be a constant value of $0.0435 \mathrm{~W} / \mathrm{m}$ $\mathrm{K}$, equal to the conductivity at the highest temperature. The dependence on temperature (figure 6) was neglected. Since the thermal conductivity is lower at lower temperatures, this assumption is conservative; the actual thermal leak through the insulation will be lower.

- The actual GPHS modules are smaller than the interior sphere, and hence fit into the interior sphere with extra (wasted) space. If this extra space is filled with insulation, the heat transfer from the interior would be reduced. Thus, modeling the GPHS as a sphere is a conservative assumption.

- Thermal resistance across the thin titanium shell is low compared to the insulation, and is neglected in this analysis.

- The thermal heat energy input from the two modules is equal to three components: heat energy lost through insulation, heat energy loss through the thermoelectrics, plus the electrical energy output to the lander, as shown in Eq. (1) and Fig. 8. The thermal heat from the two GPHS modules transfers to either the hot shoe of the thermoelectric converters or to the Microtherm insulation. The Microtherm insulation impedes heat energy from escaping. The heat energy that does escape through the Microtherm insulation travels to the exterior of the thermal enclosure, assumed to be at Venus ambient temperature. The heat energy input to the thermoelectrics is either transferred to the lander as an electrical output or wasted due to the inefficiency of the thermoelectric converters. The cooling fins radiate the waste heat to the environment of Venus. This inefficiency takes into account the thermal and electrical conductivity of the thermoelectric material. This equation assumed no mass flow.

$$
Q_{\text {in }}=Q_{\text {insulation }}+Q_{T E}+Q_{\text {elec }}
$$

- The heat energy loss through the insulation is equal to the excess heat energy radiated through the fins.

- A steady state is assumed.

- Heat transfer through the titanium wall with the gold coating is ignored.

The analysis for this case consisted of determining the components of the heat flow shown in Eq. (1). The resistance of the Microtherm insulation was modeled using Eq. (2).

$$
R=\int_{r_{i}}^{r_{f}} \frac{\rho d r}{A(r)}=\frac{\rho}{4 \pi}\left(\frac{1}{r_{i}}-\frac{1}{r_{f}}\right)
$$

The reciprocal of the thermal conductivity is the thermal resistivity of Microtherm, 23 meter Kelvin per Watt. The initial radius in Eq. (2) is the radius of the spherical model of the two stacked GPHS modules. This was calculated to be 0.0866 meters. The thickness of the Microtherm insulation equals the length of the SiGe thermoelectrics: 0.0311 meters. Therefore the outside radius of the spherical model is 0.1177 meters. These variables are used in Eq. (2) to calculate the conduction resistance: $5.58 \mathrm{~K}$ per Watt. Dividing the temperature gradient through the insulation by the resistance results in heat energy loss through the insulation. This is shown in Eq. (3).

$$
Q_{\text {insulation }}=\frac{\Delta T}{R}
$$

The temperature gradient of the thermoelectrics $(502 \mathrm{~K})$ is the same for the insulation. The heat energy loss through the Microtherm insulation was calculated to be 89.9 Watts. Subtracting the heat energy loss through the insulation from the initial thermal source strength (500 Watts) leaves 384.4 Watts transferred across the thermoelectric elements. The efficiency of the thermoelectric devices for electricity generation is calculated from the temperature and ZT value using Eq. (4):

$$
\eta=\frac{T_{H}-T_{C}}{T_{H}} \frac{\sqrt{1+Z \bar{T}}-1}{\sqrt{1+Z \bar{T}}+\frac{T_{C}}{T_{H}}}
$$

An efficiency of $6.26 \%$ was determined. The efficiency is low because of the nature of thermoelectric converters. and the high temperature of the cold side, $\mathrm{T}_{\mathrm{c}}$, causes the temperature gradient between the hot and cold shoes to 
decrease and thus decreases efficiency of the thermoelectrics. The power output for the converter is therefore 25.7 Watts. A summary of heat energy input and output is shown in table 2.

\section{Microtherm Insulation}

The mass of the Microtherm insulation is calculated from its volume and density. Using the spherical model with the inside radius 0.0866 meters and the outside radius 0.1177 meters, the volume of insulation is $0.00412 \mathrm{~m}^{3}$. The density of the Microtherm insulation was stated as $450 \mathrm{~kg} / \mathrm{m}^{3}$, resulting in a mass of $1.85 \mathrm{~kg}$ for the insulation.

\section{Titanium Wall}

Table 2. Summary of heat energy.

The mass and thickness of the spherical pressure vessel were found using Eqs. (5) and (6) respectively. The pressure difference between the inside and the outside of the pressure vessel is 920 kilopascals (92 bar). The volume of the spherical model is $0.00683 \mathrm{~m}^{3}$ (using the exterior radius of 0.1177 meters). The density of titanium is $4540 \mathrm{~kg} / \mathrm{m}^{3}$. The ultimate tensile strength of titanium was assumed to be about 200 megapascals. Using these variables the mass and thickness of the titanium wall were calculated to be 2.14 kilograms and 0.0027 meters respectively.

$$
\begin{gathered}
m_{T i}=\frac{3}{2} P V \frac{\rho_{T i}}{\sigma} \\
d_{T i}=\frac{r_{f} P}{2 \sigma}
\end{gathered}
$$

\section{Fins}

Cooling fins are sized to remove waste heat from the thermoelectric elements and transfer it to the atmosphere. The cold shoes of the thermoelectrics are connected directly to the base of the cooling fins. Convective heat transfer occurs between the cooling fins at $\mathrm{T}_{\mathrm{c}}, 773 \mathrm{~K}$ and the carbon dioxide atmosphere on Venus at $\mathrm{T}_{\mathrm{V}}, 723 \mathrm{~K}$. Sizing the cooling fins depends on many factors including: the temperature at the cold junction of the thermoelectric, the ambient temperature of Venus at the surface, the cooling fin diameter, cooling fin thickness, number of cooling fins, and the convective heat transfer coefficient to the surroundings. The following assumptions were made:

- For initial analytical purposes $1000 \mathrm{Watts}$ per $\mathrm{m}^{2}-\mathrm{K}$ was used as a rough estimate for the convective heat transfer coefficient for this study. This approximation is taken from predictions of heat transfer coefficients of supercritical carbon dioxide with lubricating oil. ${ }^{21}$

- It is assumed that the heat energy ejected to the atmosphere through the fins is equal to the waste heat from the thermoelectric elements

- It is assumed that all the heat transfer to radiate the excess heat energy from the fins is done by convection. Therefore the heat transfer area of the fins is approximated using Newton's law of cooling.

- The shape of the fins are assumed to be rectangular prisms.

- The number of fins is assumed to be 25 .

- Each fin is assumed to be tapered, with a thickness of $5 \mathrm{~mm}(0.005) \mathrm{m}$ at the root, $0.5 \mathrm{~mm}(0.0005 \mathrm{~m})$ at the tip, for an average thickness $w$ of $0.00275 \mathrm{~m}$ meters.

- Efficiency of fins is not considered.

Equation (7) combines the first two assumptions and Newton's law of cooling. Equation (8) displays the required exposed surface area of all of the fins. Using this equation, an exposed heat transfer area of $0.007695 \mathrm{~m}^{2}$ was found. (Since both sides of the fin are exposed to the atmosphere, the size of each fin is half this). The total mass of the fins is then calculated from the area times the thickness, times the density of the material, as shown in Eq. (9), to find the mass of the fins: $2.39 \mathrm{~kg}$.

$$
Q_{\text {fins }}=Q_{T E}=h A_{\text {fins }}\left(T_{C}-T_{V}\right)
$$




$$
\begin{gathered}
A_{\text {fins }}=Q_{T E} /\left(h\left(T_{C}-T_{V}\right)\right) \\
m_{\text {fins }}=V_{\text {fins }} \rho_{P G}=w\left(\frac{A_{\text {fins }}}{2}\right) \rho_{P G}
\end{gathered}
$$

\section{Final MEL:}

Each GPHS module has a mass of 1.44 kilograms $^{10}$. Assumptions were made for the masses of the SiGe thermoelectrics and the gas management valve. Mass of the insulation, titanium wall, and fins were found in previous subsections. The power distribution to the components of the lander is not analyzed. The wiring needed for the power distribution is assumed to be $10 \%$ of the total mass. Table 3 summaries a mass equipment list (MEL) for this power system. A $25 \%$ margin for growth is added to each item in the list. The margin is high because this is a new design. A Scilab script was used to perform all calculations.

The customized GPHS-RTG with 2 modules created in this study has a total mass of just under 24 kilograms, including margin.

Table 3: Final Mass Equipment List for RPS power system, Case 1

\begin{tabular}{|l|r|r|r|r|r|r|}
\hline $\begin{array}{l}\text { Description } \\
\text { Lander }\end{array}$ & \multicolumn{1}{c}{$\begin{array}{c}\text { QTY } \\
(\mathrm{kg})\end{array}$} & \multicolumn{2}{c}{$\begin{array}{c}\text { Unit Mass } \\
(\mathrm{kg})\end{array}$} & \multicolumn{2}{c}{$\begin{array}{c}\text { Basic Mass } \\
(\mathrm{kg})\end{array}$} & $\begin{array}{r}\text { Growth } \\
(\mathrm{kg})\end{array}$ \\
\hline Power Subsystem & & & & & \multicolumn{2}{c}{$\begin{array}{c}\text { Growth } \\
\mathbf{2 3 . 7 8}\end{array}$} \\
\hline GPHS & 2 & 1.44 & 2.88 & $25 \%$ & 0.72 & 3.60 \\
\hline Microtherm Insulation & 1 & 1.85 & 1.85 & $25 \%$ & 0.46 & 2.31 \\
\hline SiGe TE & 64 & 0.10 & 6.40 & $25 \%$ & 1.60 & 8.00 \\
\hline Gas Valve & 1 & 1.00 & 1.00 & $25 \%$ & 0.25 & 1.25 \\
\hline Titanium Cover & 1 & 2.14 & 2.14 & $25 \%$ & 0.54 & 2.68 \\
\hline Fins & 1 & 2.38 & 2.38 & $25 \%$ & 0.60 & 2.98 \\
\hline Wiring & 1 & 2.38 & 2.38 & $25 \%$ & 0.59 & 2.97 \\
\hline
\end{tabular}

\section{Recommendations}

- A more in depth-analysis of the GPHS-RTG system needs to be done. The spherical model used for the RPS was useful for initial analytical purposes for this study. The GPHS modules will be rectangular prisms of dimensions $9.96 \mathrm{~cm}$ by $9.43 \mathrm{~cm}$ by $5.82 \mathrm{~cm}$ each. The final schematic of the insulation around the modules will also most likely not be a spherical structure. A spherical structure would be difficult to manufacture but a cylindrical shape would be easier. Heat energy loss through insulation and thermoelectrics of the final and actual RPS structure must be calculated again.

- This study did not analyze the arrangement of the thermoelectrics surrounding the GPHS modules. Further review of this mission will require this analysis.

- This study found a general approximation for the size and mass of the fins. Sizing the fins again will require finding an exact heat transfer coefficient.

- This study also did not look into the arrangement of the fins around the customized GPHS-RTG. Number of cooling fins, fin thickness, and fin length should be optimized.

- Properties of Titanium at Venus ambient temperature and pressure should be used in future calculations.

- Analysis of the power management and distribution for Case 1 should be performed.

\section{E. Case 2: Primary Batteries}

Case 2 analyzes powering the mission with primary batteries. This may be a better choice if the amount of time the lander needs to collect a sufficient amount of data is within the lifespan of the battery. Primary batteries are useful for short duration missions or long term tasks that use very little power. The mission duration is 117 days. 
The batteries will not be recharged. Therefore the battery mass needed for 117 days will play a significant role in deciding if this is a feasible case.

Primary batteries for use on Venus were analyzed by Landis and Harrison ${ }^{22}$. Possible batteries considered were Sodium Nickel Chloride batteries, Lithium-Thionyl Chloride batteries, and Sodium Sulfur batteries. Lithium-Thionyl Chloride batteries were not analyzed further because their maximum temperature rating was 200 degrees Celsius $(473 \mathrm{~K})$, well below the ambient temperature at the surface of Venus. Sodium Nickel Chloride batteries, although they have been projected to operate at 500 degrees Celsius $(773 \mathrm{~K})$, had a smaller projected specific energy (200 Watt hours per kilogram) than the Sodium Sulfur batteries (300 Watt hours per kilogram). ${ }^{23} \mathrm{NaS}$ batteries have also been tested in space on the space shuttle flight STS-87 in November 1997. Therefore Sodium Sulfur batteries were chosen for Case 2.

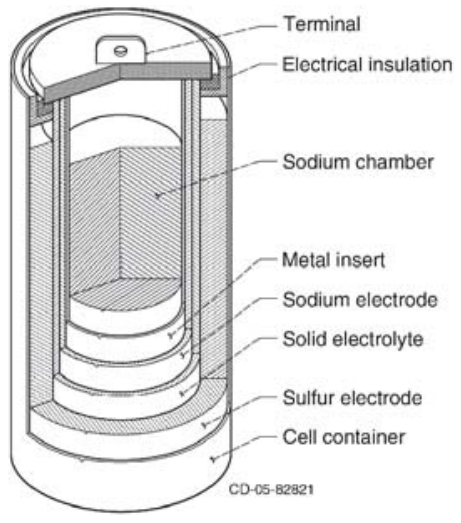

Figure 9. Schematic cutaway of a NaS battery.

\section{NaS batteries}

Figure 9 is a schematic cutaway of a NaS battery. This battery consists of a sodium anode, a solid beta alumina separator and electrolyte, and a sulfur cathode. At Venus conditions of 450 degrees Celsius (723 K) and 92 bar pressure, the reaction reactants (Sodium and Sulfur) and products (sodium sulfide) are all in liquid-liquid phase, which is needed for the reaction to occur. ${ }^{24}$ Therefore the NaS battery meets the second requirement because it operates at the conditions found on the surface of Venus. To estimate the battery mass needed for this mission, the following assumptions were used:

- $\quad$ Baseline estimate of power required: 20 Watts.

- $\quad$ Mission duration: 117 Earth days, (2808 hours).

- $\quad$ Energy efficiency of $80 \% .^{23}$

- $\quad$ Specific energy of 300 Watt hours per kilogram. ${ }^{23}$

Using these variables, an approximate battery capacity and battery mass were calculated to be 70200 Watt hours and 234 kilograms respectively using Eqs. (10) and (11).

$$
\begin{gathered}
C_{b a t}=\frac{P_{b a t} T_{b a t}}{\eta_{c o n v}} \\
m_{b a t}=\frac{C_{b a t}}{\Gamma_{b a t}}
\end{gathered}
$$

As with Case 1, the power management and distribution for Case 2 is assumed to be $10 \%$ of the total mass. Therefore the mass for power distribution is 25 $\mathrm{kg}$, and the final mass of Case 2 is $260 \mathrm{~kg}$.

Due to the mass, this power system is large and cumbersome compared to Case 1. Figures 10 and 11 display the possible battery mass if the power required and mission duration are varied. If the mission duration of 117 days is a requirement, the power required must be reduced in order to minimize the battery mass. Table 4 displays various battery masses needed for a range of power required. If the power required is reduced to 5 Watts, then the battery mass, 58.5 kilograms, is comparable to the total mass of Case 1.

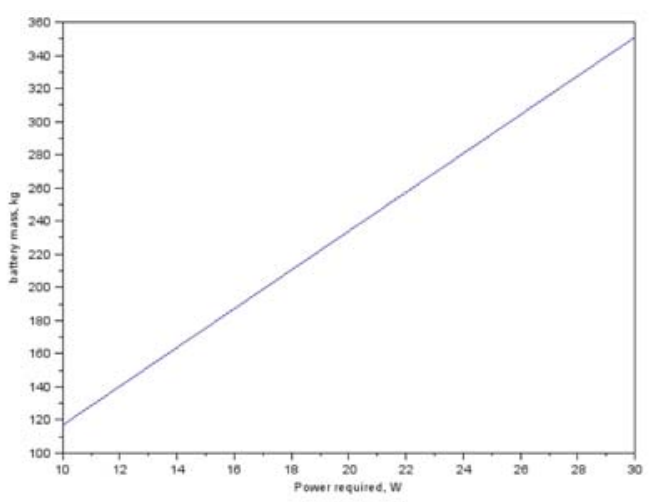

Figure 10. Power required versus battery mass.

1.

American Institute of Aeronautics and Astronautics 


\section{Recommendations}

A few recommendations are suggested. Depth of discharge of the NaS batteries was not considered in the analysis and should be incorporated. Degradation of the battery over 117 days should be studied. Analysis of the power management and distribution for Case 1 should be performed.

\section{Conclusion}

This study focused on the power system for a future long-duration Venus lander. The requirements for the power system included: mission duration of 1 Venus solar day (117 Earth days), operation at Venus ambient temperature and pressure, protection from corrosion, selection of a system with no moving parts, and location at the pole. The assumptions of the power system included providing no cooling to the high temperature electronics and components of the lander and assuming an initial baseline low power level of 20 Watts. The assumption that no cooling is provided to the lander requires high-temperature electronics, an assumption not included in previous mission concept studies.

Two cases were considered for this study. A customized GPHS-RTG was chosen for the first case.

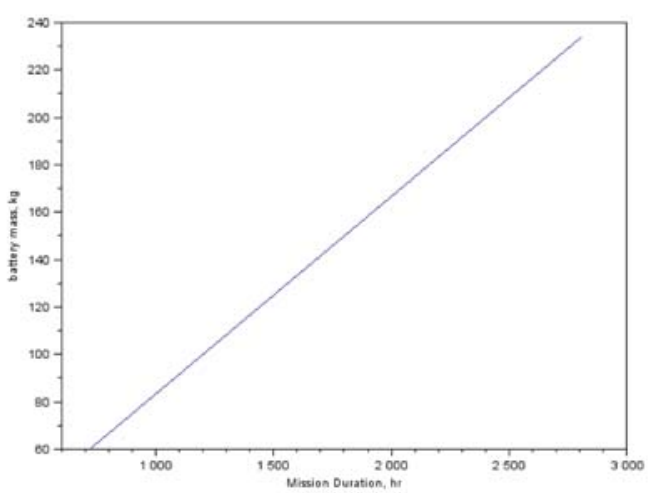

Figure 11. Mission duration versus battery mass.

Table 4: Battery mass for a range of power required.

\begin{tabular}{|c|c|}
\hline Power Required $(\mathrm{W})$ & Battery Mass $(\mathrm{kg})$ \\
\hline 5 & 58.5 \\
\hline 10 & 117 \\
\hline 20 & 234 \\
\hline 30 & 351
\end{tabular}

Its design consisted of 2 GPHS modules, Microtherm insulation, a titanium pressure vessel wall, gold coating on the wall, $64 \mathrm{SiGe}$ thermoelectrics, a gas management valve, and 25 cooling fins. A simplified spherical model was assumed to perform the thermal analysis and calculate each component from the conservation of energy assumption. The heat energy loss through the insulation was calculated to be 89.94 Watts, leaving 384.38 Watts for the thermoelectrics to work with. The efficiency of the thermoelectrics was determined to be $6.26 \%$, resulting in electrical output to the lander of 25.68 Watts and final mass of the power system of 23.78 kilograms.

Sodium sulfur batteries were chosen for Case 2, with an assumed specific energy of $300 \mathrm{~W}-\mathrm{hrs} / \mathrm{kg}$. For a power requirement of 20 Watts and mission duration of 117 Earth days, total battery mass required was 234 kilograms. The battery mass required could be reduced significantly if power required or mission duration or both were also reduced.

Comparing the two cases boils down to three factors: risk, science return, and cost. The RPS design for Case 1 needs to be further analyzed, developed, built, and tested. On the other hand the battery design for Case 2 already exists, although it needs to be validated for Venus operation, in a facility such as the Glenn Extreme Environment Rig (GEER). ${ }^{11}$

The primary battery power system wins in the near-term, risk-adverse case. However battery mass is directly proportional to the design lifetime whereas the RPS will survive much longer than the intended 117 days requirement. The possible longer lifetime of the RPS translates to the ability to collect more science return from the lander. The RPS case wins in the longer-term, because of its higher science return.

Cost is a third factor when comparing the two cases. The total masses for Case 1 and 2 are 24 kilograms and 260 kilograms respectively. Therefore, when it comes to launch cost, Case 1 will cost significantly less than Case 2. However, if the mission duration and/or power required are reduced, then the battery power system becomes more attractive. If the power requirement can be reduced to 5 Watts. the required battery mass becomes 58.5 kilograms.

In conclusion, both cases have their benefits and disadvantages for different mission scenarios. It is too early in the design process to select one over the other.

\section{Acknowledgments}

The authors would like to acknowledge the work of Nathan Boll and Christopher Stelter on the "HADES" conceptual design project for a Venus lander (reference 3), which was the original instigation of this work. We thank Steven R. Oleson and Paul C. Schmitz for their invaluable help. They would also like to acknowledge the NASA Space Academy and the Texas Space Grant Consortium who made this work possible. 


\section{References}

${ }^{1}$ Committee on the Planetary Science Decadal Survey, Space Studies Board, Division on Engineering and physical Sciences, Vision and Voyages for Planetary Science in the Decade 2013-2022, The National Academies Press, Washington, D. C., 2011.

${ }^{2}$ Hunten; D. M., Colin, L., Donahue, T. M., and Moroz, V. I. (eds.), Venus, University of Arizona Press, 1983.

${ }^{3}$ Boll, N., et al., "Venus High Temperature Atmospheric Dropsonde and Extreme Environment Seismometer (HADES), to be presented, 65th International Astronautical Congress, Toronto ON, Sept. 30-Oct. 2, 2014.

${ }^{4}$ Jakosky, B. M., "Atmospheres of the Terrestrial Planets", in Beatty, Petersen and Chaikin (eds.), The New Solar System, 4th edition, Sky Publishing Company, 1999, pp. 175-200.

${ }^{5}$ Stofan, E. R., Saunders, R. S., Senske, D., Nock, K., Tralli, D., and Lundgren, P., "Venus Interior Structure Mission (VISM): Establishing a seismic network on Venus," Workshop on Advanced Technologies for Planetary Instruments, Lunar and Planetary Institute, Part 1 p 23-24 (SEE N93-28764 11-91), 1993.

${ }^{6}$ Landis, G. A., "Robotic Exploration of the Surface and Atmosphere of Venus," paper IAC-04-Q.2.A.08, Acta Astronautica, Vol. 59, No. 7, pp. 517-580 (October 2006).

${ }^{7}$ Lorenz, R. D., Mehoke, D., and Hill, S., "Venus Pathfinder: a Stand-Alone Long-Lived Venus Lander Concept," $8^{\text {th }}$ International Planetary Probe Workshop (IPPW-8), Portsmouth, VA, June 6-10, 2011.

${ }^{8}$ Landis, G. A., Dyson, R., Oleson, S., Warner, J., Colozza, A., and Schmitz, P., "Venus Rover Design Study," paper AA 2011-7268, AIAA Space 2011 Conference \& Exposition, Long Beach CA, Sept. 26-29, 2011.

${ }^{9}$ Colozza, A. J. "Radioisotope Stirling Engine Powered Airship for Low Altitude Operation on Venus," NASA/CR2012-217665 (2012).

${ }^{10}$ Oleson, S. R. “COMPASS Final Report: Advanced Lithium Ion Venus Explorer (ALIVE),” NASA CD-2012-72.

${ }^{11}$ Dyson, R. W., and Bruder, G. A. "Progress Towards the Development of a Long-Lived Venus Lander Duplex System," AIAA-2010-6917, 8th International Energy Conversion Engineering Conference (IECEC), Nashville, TN, July 25-28 2010. NASA TM-2011-217018.

${ }^{12}$ Hunter, G. W., Neudeck, P. G., Okojie, R. S., Beheim, G. M., Krasowski, M. J. Ponchak, G. E. and Chen, L.-Y., "High Temperature Electronics, Communications, and Supporting technologies for Venus Missions," 5th International Planetary Probe Workshop, IPPW-5, Bordeaux, France; June 23-29 1997.

${ }^{13}$ Neudeck, P. G., Okojie, R. S., Chen, L.-Y. and Liang-Yu, "High-Temperature Electronics-A Role for Wide Bandgap Semiconductors," Proceedings of the IEEE, Vol. 90, No. 6, June 2002

${ }^{14}$ Landis, G. A. and Haag, E. "Analysis of Solar Cell Efficiency for Venus Atmosphere and Surface Missions," AIAA $11^{\text {th }}$ International Energy Conversion Engineering Conference. San Jose, CA, July 15-17 2013.

${ }^{15}$ Balint, T. S., "Radioisotope Power Systems for In-Situ Exploration of Titan and Venus," $4^{\text {th }}$ International Planetary Probe Workshop, Pasadena, CA, June 27-30 2006.

${ }^{16}$ Antonio Sanchez-Torres, A., "Radioisotope Power Systems for Space Applications", Radioisotopes -Applications in Physical Sciences, Prof. Nirmal Singh (ed.), ISBN: 978-953-307-510-5, InTech, (2011). Available from: http://www.intechopen.com/books/radioisotopes-applications-in-physical-sciences/radioisotope-powersystems-forspace-applications 
${ }^{17}$ Bennet, G. L., et al.,. "Mission of Daring: The General Purpose Heat Source Radioisotope Thermoelectric Generator," AIAA 2006-4096, $4^{\text {th }}$ International Energy Conversion Engineering Conference and Exhibit (IECEC), San Diego, CA, June 26-29, 2006.

${ }^{18}$ Angelo, J. A. Jr., Buden, D., Space Nuclear Power, $1^{\text {st }}$ ed., Orbit Book Company, Inc, Malabar, Florida, 1985, pp. 9, 152-154.

${ }^{19}$ Dughaish, Z. H. "Lead Telluride as a thermoelectric material for thermoelectric power generation,." Physica B 322 (2002) 205-223.

${ }^{20}$ Tritt, T. M., Subramanian, M. A. "Thermoelectric Materials, Phenomena, and Applications: A Bird's Eye View," MRS Bulletin. Volume 31, March 2006.

${ }^{21}$ Dang, C., and Hihara, E., "Prediction of Cooling Heat Transfer Coefficient of Supercritical CO2 With Small Amount of Entrained Lubricating Oil Entrained by Neural Network Method." Purdue University. 2008.

International Refrigeration and Air Conditioning Conference. Paper 908. http://docs.lib.purdue.edu/iracc/908

${ }^{22}$ Landis, G. A., and Harrison, R., "Batteries for Venus Surface Operation," Journal of Propulsion and Power. Vol. 26, No. 4. July-August 2010.

${ }^{23}$ Hall, J. L., Bullock, M., Senske., D. A., Cutts, J. A., Grammier, R., et al., "Venus Flagship Mission Study,” NASA Jet Propulsion Laboratory, California Institute of Technology, April 17, 2009.

${ }^{24}$ Sudworth, J. L., and Tilley, A. R., The Sodium Sulfur Battery, Chapman and Hall, London, 1985. 